\title{
Public Preferences for Government Response Policies on Outbreak Control
}

\author{
Semra Ozdemir ${ }^{1,2,3}$ (D) Si Ning Germaine $\operatorname{Tan}^{1,2} \cdot$ Isha Chaudhry $^{1,2} \cdot$ Chetna Malhotra $^{1,2} \cdot$ Eric Andrew Finkelstein $^{1,2,3,4}$
}

Accepted: 24 December 2020 / Published online: 10 April 2021

(c) The Author(s), under exclusive licence to Springer Nature Switzerland AG 2021

\begin{abstract}
Objective The aim of this study was to assess the extent to which public support for outbreak containment policies varies with respect to the severity of an infectious disease outbreak.

Methods A web-enabled survey was administered to 1017 residents of Singapore during the coronavirus disease 2019 (COVID-19) pandemic, and was quota-sampled based on age, sex, and ethnicity. A fractional-factorial design was used to create hypothetical outbreak vignettes characterised by morbidity and fatality rates, and local and global spread of an infectious disease. Each respondent was asked to indicate which response policies (among five policies restricting local movement and four border control policies) they would support in five randomly assigned vignettes. Binomial logistic regressions were used to predict the probabilities of support as a function of outbreak attributes, personal characteristics, and perceived policy effectiveness.

Results Likelihood of support varied across government response policies but was generally higher for border control policies compared with internal policies. The fatality rate was the most important factor for internal policies, while the degree of global spread was the most important for border control policies. In general, individuals who were less healthy, had higherincome, and were older were more likely to support these policies. Perceived effectiveness of a policy was a consistent and positive predictor of public support.

Conclusions Our findings suggest that campaigns to promote public support should be designed specifically to each policy and tailored to different segments of the population. They should also be adapted based on the evolving conditions of the outbreak in order to receive continued public support.
\end{abstract}

\section{Introduction}

In deploying response policies to contain an infectious disease outbreak, governments have to balance controlling its spread against restricting personal liberty [1,2] and adverse economic outcomes [3]. This is especially so

Semra Ozdemir

semra.ozdemir@duke-nus.edu.sg

1 Programme in Health Services and Systems Research, DukeNUS Medical School, 8 College Road, Singapore 169857, Singapore

2 Lien Centre for Palliative Care, Duke-NUS Medical School, 8 College Road, Singapore 169857, Singapore

3 Saw Swee Hock School of Public Health, National University of Singapore, 12 Science Drive 2, Singapore 117549, Singapore

4 Duke University Global Health Institute, Duke University, 310 Trent Drive, Durham, NC 27710, USA

\section{Key Points}

The support for any policy for containment of an infectious disease outbreak was mainly influenced by characteristics of that outbreak.

These findings suggest that governments should be mindful that the public's support for policies may change as an outbreak evolves.

An individual's perception of a policy's effectiveness as an outbreak control strategy was the most consistent predictor of support for all policies in our study. 
for outbreaks that spread by respiratory droplets. Governments have to adapt and adjust policies at different phases of an outbreak, and, in most cases, with limited and evolving information. In doing so, governments are concerned about the public opinions of their constituencies, especially when public support is paramount to ensuring successful implementation of these policies [2, 4-6]. Only a handful of studies have investigated public support for government containment policies for a pandemic and the factors that influence acceptance [6-9]; however, they did not investigate public support for more restrictive policies, such as shutting down public transportation or initiating a lockdown, which have been implemented in multiple countries during the coronavirus disease 2019 (COVID19) pandemic. Additionally, only one study [8] found how public support for government measures varied with respect to pandemic characteristics, and only one study was actually conducted during a pandemic [9].

The main objective of this study was to assess the extent to which public support for government response measures varied with respect to the severity of an infectious disease outbreak that transmits primarily by respiratory droplets. The survey was administered to an adult sample of Singapore's general population during the initial stages of the COVID-19 pandemic. This provided the unique opportunity to capture public opinion during a period of potential physical, psychological, and financial turmoil of an outbreak-turned-pandemic [10-13].

An individual's support of a specific public health policy likely depends on how they perceive its benefits and costs to their household, community, and to society [14]. We hypothesize that public support for a specific outbreak control policy will be higher as per rates of morbidity and fatality within the country and its spread locally and across the world. We also hypothesize that fatality rate will be the most important factor for internal policies, while global spread will be the most important factor for border control policies.

We also investigated how the likelihood of support varies with personal characteristics. An earlier study indicates that individuals with lower-income are less likely to support government response policies [6], possibly because they are more likely to experience loss of income due to these policies [15]. All else equal, older and less-healthy individuals are more likely to support government policies as they are more vulnerable and adversely affected by infectious diseases than younger and healthier individuals $[16,17]$. Since income and health effects are expected to work in opposite directions, we investigated which is more dominant. The uncertainty associated with the risk of infection among young children and the absence of an immediate vaccine or cure resulted in lockdown, including school closures $[18,19]$. Therefore, we also investigated whether individuals living with children are more likely to support the policies on school closure and national lockdown. Lastly, literature also showed that measures perceived to be more effective (e.g. frequent handwashing and mask wearing) were practiced more compared with those that were not perceived to be so (e.g. working from home) $[20,21]$. Hence, we also investigated whether individuals who perceive specific policies to be effective are more likely to support them.

\section{Methods}

\subsection{Study Sample}

A web-enabled survey was administered by a major market research company to their panel members, which accounts for nearly $2.5 \%$ of the total Singaporean population. Respondents had to be of legal age in Singapore ( $\geq 21$ years) and residents of Singapore. We quota-sampled based on sex, age, and ethnicity, with $\pm 5 \%$ error margin to ensure national representation. All respondents provided written consent and received points-based rewards (approximately US\$5.00) from the survey company. The study was exempted from review by the Institutional Review Board of the National University of Singapore (reference: S-20-085). The survey was fielded between 31 March and 14 April 2020 during the COVID-19 pandemic. When the survey was launched on 31 March, there were 926 confirmed cases of COVID-19 and three COVID-related deaths in Singapore [22].

\subsection{Survey Development}

Respondents were shown five vignettes describing the early days of an outbreak. Each vignette was characterized using five attributes (electronic supplementary material A). Two attributes described the degree of spread of the disease both locally and globally, respectively: 'Total number of confirmed cases in Singapore since the outbreak started' and 'Number of countries with rapidly increasing number of cases'. One attribute described the trend of the local disease spread: 'Number of new cases in Singapore within the last 2 weeks', and two others described the morbidity and fatality of the disease: 'Number of cases admitted to intensive care unit (ICU) but did not end in death in Singapore' and 'Number of infection-related deaths in Singapore'. Number of new cases in Singapore, number of cases admitted to the ICU, and number of infection-related deaths were calculated as a percentage of the 'total number of confirmed cases in Singapore' attribute.

A fractional-factorial design was created, and each respondent was randomly assigned to one of the 10 blocks with five vignettes. For each vignette, respondents were 
asked to select which policies the government should implement. The policies included five internal policies restricting movement within the country, and four border control policies. These policies were selected based on the policies implemented during COVID-19 or previous pandemics in Singapore as well as others considered at the time of the survey development. Figure 1 presents an example vignette.

We also asked questions on socioeconomic demographics, overall health status, and participants' perception of each specific policy's ability to prevent the spread of COVID19 in the community. More information on the selection of attribute levels is reported in electronic supplementary material B.

\subsection{Statistical Analysis}

We used binomial logistic regressions to estimate the probability of choosing a policy where ' 1 ' $=$ support for the policy and ' 0 ' $=$ no support. Since each respondent was shown multiple vignettes, to account for the selections by the same respondent, the regressions were estimated with clustered standard errors where the clustering was based on respondent identification.

The independent variables included five outbreak-related attributes and personal characteristics. The main effects and interaction effects on outbreak attributes were entered into the model as continuous variables. Based on our research questions, the perceived effectiveness of a policy ('very effective' vs. 'somewhat effective'/'not effective'), age, living with young children (yes vs. no), self-reported health status (poor/fair vs. good/very good/excellent), and income were included as predictors. We used housing type as a proxy for income categorization (lower- vs. higher-income) since it was less likely to be affected by the short-term effects of COVID-19. We also investigated the interaction effects between health and income dummy variables to investigate whether income-related concerns moderate the effect of health concerns (and vice versa). A nationwide partial lockdown that implemented most of the policies discussed in this study started on 7 April 2020. We thus added a dummy variable indicating 'those who completed the survey after start of partial lockdown'.

First, we presented the percentage of times each policy was selected by the respondents (averaged over all vignettes). Since the interpretation of coefficients is complicated when a logistic model has both main and interaction effects, we calculated the average marginal effects for the outbreak attributes to identify the relative importance of each attribute. The average marginal effects provide the average change in probability of policy support for the sampled population when an attribute increases by one unit [23, 24]. We also predicted the average probability of support (i.e. choosing a policy) for each policy under four scenarios (two that are less severe and two that are more severe) to show how the likelihood of support changes based on the varying severity of the outbreak. To assess the effects of health and income on policy support, we presented the average predicted probabilities for different subpopulations (e.g. lesshealthy and low-income groups). Lastly, we presented the average marginal effects of age, perceived effectiveness of a policy, and living with children on the likelihood of support. Stata 16.1 (StataCorp LLC, College Station, TX, USA) was used to perform the analyses.

\section{Results}

\subsection{Respondent Characteristics}

Overall, 1017 respondents completed the survey. Over half $(51 \%)$ of the respondents were female (Table 1), and the majority $(80.1 \%)$ were Chinese, with a median age of 40 years. Distribution of age groups was relatively uniform, with $35.2 \%$ aged between 21 and 35 years, $35.4 \%$ aged between 36 and 50 years, and $29.4 \%$ aged over 50 years. Overall, the sample was representative of the national population for sex (51\% females) and age (median 41.1 years), but overrepresented Chinese ethnicity ( $74.3 \%$ of the population) [25]. More than half were married (55.7\%) and over half the sample had a university degree (58.1\%). Over one-third of the respondents $(36.2 \%)$ were living with young children ( $<12$ years). Most respondents (67.4\%) were employed full-time, while $15 \%$ were employed part-time or were selfemployed. Based on housing type, $19.5 \%$ were categorized as lower-income, $59.3 \%$ were categorized as middle-income, and $21.2 \%$ were categorized as higher-income. The distribution of housing type in our sample is similar to national statistics on housing [26]. About 17\% reported having fair or poor health status at the time of the survey.

We observed variation in perceived effectiveness of each policy reported by the respondents (Table 2). The policies that received the highest proportions of the "very effective' rating were 'no entry of visitors from countries with rapidly increasing number of cases' (henceforth referred to as banning visitors from selected countries) [75.7\%] and 'quarantine of residents returning from countries with rapidly increasing number of cases' (henceforth referred to as quarantining residents from selected countries) $[70.2 \%]$. The policies that received the lowest proportions of 'very effective' rating were shutting down public transportation (32.1\%) and 'no gatherings of more than 50 people' (henceforth referred to as banning large gatherings) [39.4\%]. 
Fig. 1 Example vignette

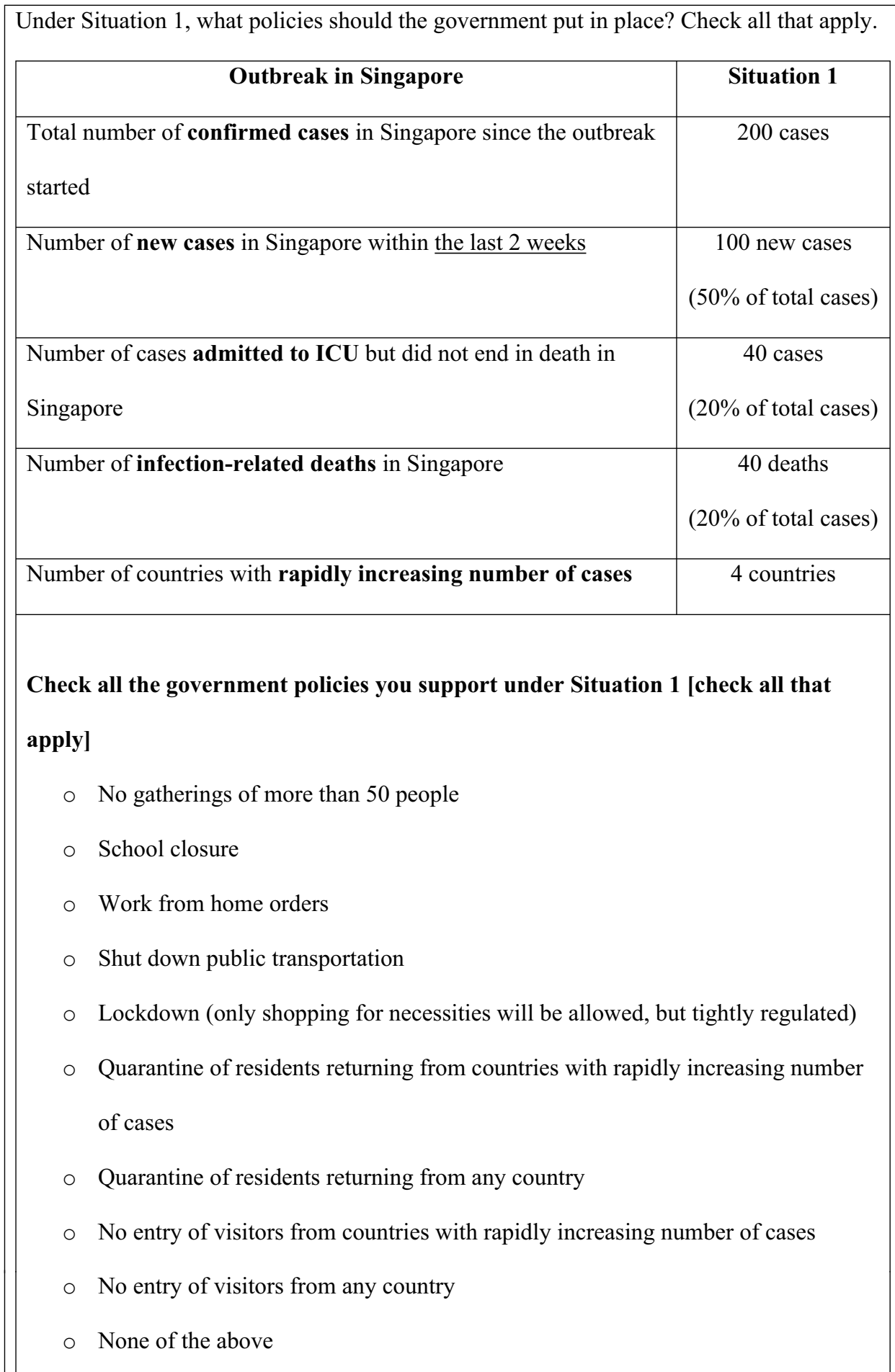

\subsection{Vignette Findings}

Table 2 presents the percentage of times each policy was selected. The most-selected policies were quarantining residents from selected countries $(80.7 \%)$ and banning visitors from selected countries $(78.6 \%)$. The least-selected policies were shutting down public transportation (30.4\%), followed by lockdown (45.1\%). We also found that for each policy, 2.4-5.5\% of respondents failed to choose a policy in a more severe scenario, but they chose the same policy in a less severe scenario (Table 2 ). We conducted sensitivity analysis by excluding these responses from the analysis. 
Table 1 Demographic characteristics $[N=1017]$

\begin{tabular}{|c|c|}
\hline \multicolumn{2}{|l|}{ Characteristic } \\
\hline Female & $519(51.0)$ \\
\hline Age, years [median (IQR)] & $40(32-52)$ \\
\hline \multicolumn{2}{|l|}{ Ethnicity } \\
\hline Chinese & $815(80.1)$ \\
\hline Malay & $91(9.0)$ \\
\hline Indian + others & $111(10.9)$ \\
\hline Married & $567(55.7)$ \\
\hline \multicolumn{2}{|l|}{ Education } \\
\hline Below secondary & $139(13.7)$ \\
\hline Vocational/diploma & $287(28.2)$ \\
\hline University or above & $591(58.1)$ \\
\hline \multicolumn{2}{|l|}{ Employment } \\
\hline Full-time & $686(67.4)$ \\
\hline Part-time/self-employed & $153(15.0)$ \\
\hline Others & $178(17.5)$ \\
\hline \multicolumn{2}{|l|}{ Housing type (proxy for income) } \\
\hline 1- to 3-bedroom public housing (lower-income) & $198(19.5)$ \\
\hline 4- to 5-bedroom public housing (middle-income) & $603(59.3)$ \\
\hline Private housing (higher-income) & $216(21.2)$ \\
\hline \multicolumn{2}{|l|}{ Living with young children $(<12$ years $)$} \\
\hline Yes & $368(36.2)$ \\
\hline No & $649(63.8)$ \\
\hline \multicolumn{2}{|l|}{ Current health status } \\
\hline Excellent/very good & $383(37.7)$ \\
\hline Good & $459(45.1)$ \\
\hline Fair/poor & $175(17.2)$ \\
\hline
\end{tabular}

Data are expressed as $n(\%)$ unless otherwise specified

$I Q R$ interquartile range
Results from the logistic regressions are reported in electronic supplementary material $\mathrm{C}$. Table 3 shows the average marginal effects for all policies. As we hypothesized, the fatality attribute had the highest average marginal effects for most internal policies, with the largest effect observed for lockdown $(0.0054, p<0.001)$, followed by school closure $(0.0048, p<0.001)$; however, the attribute was not significant for banning large gatherings $(-0.0002, p=0.82)$. The number of countries with a rapidly increasing number of cases had the highest average marginal effects for three (out of four) border control policies, and the largest effect was observed for 'no entry of visitors from any country' (henceforth known as banning all visitors) [0.0063, $p<0.001]$, followed by quarantining residents returning from any country [0.0050, $p<0.001]$.

The average predicted probabilities of support (including 95\% confidence interval [CI]) for each policy in four different scenarios are shown in Fig. 2 (the full list of probabilities, CIs, and $p$ values are reported in electronic supplementary material D). Scenarios 1 and 4 were the least and most severe scenarios, respectively, and therefore should receive the lowest and highest probabilities of support accordingly for each policy. The number of countries with rapidly increasing cases was kept constant (at four) across all the scenarios to highlight the variation in predicted probabilities due to country-specific factors only.

Among internal policies, the probability of support for the least severe scenario (Scenario 1) was the highest for banning large gatherings (0.67 [0.63-0.70]), followed by work from home orders $(0.53$ [0.49-0.57]), and lowest for shutting down public transportation $(0.17$ [0.15-0.20]) [Fig. 2]. The probability of support was greater in scenarios with more severe outbreak scenarios for all policies, except for banning large gatherings. The steepest increase in support from Scenario 1 to Scenario 4 was for

Table 2 Perceived effectiveness of a policy and percentage of times a policy was selected $[N=1017]$

\begin{tabular}{|c|c|c|c|}
\hline Policy & $\begin{array}{l}\text { Perceived effectiveness of } \\
\text { policy [very effective] (\%) }\end{array}$ & $\begin{array}{l}\text { Percentage of times a } \\
\text { policy was selected (\%) }\end{array}$ & $\begin{array}{l}\text { Percentage of respondents } \\
\text { who failed the validity } \\
\text { test }(\%)\end{array}$ \\
\hline No gatherings of more than 50 people & 39.4 & 74.3 & 5.5 \\
\hline School closure & 41.0 & 55.7 & 3.5 \\
\hline Work-from-home orders & 54.9 & 71.4 & 3.6 \\
\hline Shut down public transportation & 32.1 & 30.4 & 3.2 \\
\hline $\begin{array}{l}\text { Lockdown (only shopping for necessities will be allowed, } \\
\text { but tightly regulated) }\end{array}$ & 52.4 & 45.1 & 2.4 \\
\hline $\begin{array}{l}\text { Quarantine of residents returning from countries with a rap- } \\
\text { idly increasing number of cases (i.e. selected countries) }\end{array}$ & 70.2 & 80.7 & 4.9 \\
\hline Quarantine of residents returning from any country & 67.2 & 75.6 & 3.6 \\
\hline $\begin{array}{l}\text { No entry of visitors from countries with a rapidly increasing } \\
\text { number of cases (i.e. selected countries) }\end{array}$ & 75.7 & 78.6 & 4.1 \\
\hline No entry of visitors from any country & 68.2 & 64.9 & 4.0 \\
\hline
\end{tabular}


Table 3 Average marginal effects for outbreak attributes [ $N=1017]$

\begin{tabular}{|c|c|c|c|c|c|}
\hline & $\begin{array}{l}\text { Total no. of con- } \\
\text { firmed cases }\end{array}$ & $\begin{array}{l}\text { No. of new cases in the } \\
\text { last } 2 \text { weeks }\end{array}$ & $\begin{array}{l}\text { No. of cases admitted } \\
\text { to the ICU }\end{array}$ & $\begin{array}{l}\text { No. of infection- } \\
\text { related deaths }\end{array}$ & $\begin{array}{l}\text { No. of countries with a } \\
\text { rapidly increasing number of } \\
\text { cases }\end{array}$ \\
\hline \multicolumn{6}{|c|}{ No gatherings of more than 50 people } \\
\hline AME & 0.0001 & 0.0008 & 0.0000 & -0.0002 & 0.0015 \\
\hline$p$ value & 0.0000 & 0.0020 & 0.9770 & 0.8220 & 0.0200 \\
\hline \multicolumn{6}{|c|}{ School closure } \\
\hline AME & 0.0002 & 0.0017 & 0.0014 & 0.0048 & 0.0042 \\
\hline$p$ value & 0.0000 & 0.0000 & 0.0540 & 0.0000 & 0.0000 \\
\hline \multicolumn{6}{|c|}{ Work from home orders } \\
\hline AME & 0.0001 & 0.0012 & 0.0016 & 0.0044 & 0.0043 \\
\hline$p$ value & 0.0000 & 0.0000 & 0.0220 & 0.0000 & 0.0000 \\
\hline \multicolumn{6}{|c|}{ Shut down public transportation } \\
\hline AME & 0.0001 & 0.0007 & 0.0005 & 0.0032 & 0.0003 \\
\hline$p$ value & 0.0000 & 0.0180 & 0.5010 & 0.0000 & 0.6080 \\
\hline \multicolumn{6}{|l|}{ Lockdown } \\
\hline AME & 0.0002 & 0.0012 & 0.0011 & 0.0054 & 0.0020 \\
\hline$p$ value & 0.0000 & 0.0000 & 0.1390 & 0.0000 & 0.0030 \\
\hline \multicolumn{6}{|c|}{ Quarantining residents returning from selected countries } \\
\hline AME & 0.0000 & 0.0001 & 0.0001 & -0.0010 & -0.0001 \\
\hline$p$ value & 0.1710 & 0.8240 & 0.8290 & 0.0710 & 0.8400 \\
\hline \multicolumn{6}{|c|}{ Quarantining residents returning from any country } \\
\hline AME & 0.0000 & 0.0007 & 0.0006 & 0.0016 & 0.0050 \\
\hline$p$ value & 0.0000 & 0.0150 & 0.4060 & 0.0150 & 0.0000 \\
\hline \multicolumn{6}{|c|}{ No entry of visitors from selected countries } \\
\hline AME & 0.0000 & 0.0001 & -0.0001 & 0.0010 & 0.0012 \\
\hline$p$ value & 0.0000 & 0.5750 & 0.8770 & 0.1010 & 0.0610 \\
\hline \multicolumn{6}{|c|}{ No entry of visitors from any country } \\
\hline AME & 0.0001 & 0.0005 & 0.0012 & 0.0013 & 0.0063 \\
\hline$p$ value & 0.0000 & 0.1010 & 0.0910 & 0.0770 & 0.0000 \\
\hline
\end{tabular}

$I C U$ intensive care unit, $A M E$ average marginal effects

lockdown (from 0.24 [0.21-0.27] to 1.00 [0.99-1.00]), followed by shutting down public transportation (from 0.17 [0.15-0.20] to 0.89 [0.49-1.00]).

Among border control policies, the probability of support in Scenario 1 was highest for quarantining residents from selected countries (0.81 [0.78-0.84]), and lowest for banning all visitors $(0.53$ [0.49-0.57]). The probabilities for Scenario 1 for border control policies were generally higher than the probabilities for internal policies. Banning all visitors had the steepest increase in probability from Scenario 1 to Scenario 4 (from 0.53 [0.49-0.57] to 0.97 [0.84-1.00]).

Sensitivity analysis showed that dropping the irrational responses eliminated the disordering in the average predicted probability of support for severe outbreak scenarios for policies on banning large gatherings and quarantining residents from selected countries (Fig. 3).
Among respondent characteristics, the lower-income dummy variable was significant and negative for quarantining residents from selected countries and banning visitors from selected countries $(p<0.05)$, while the middle-income dummy variable was not significant for any of the policies $(p>0.10)$. The less-healthy dummy variable was significant and positive for all four border control policies $(p<0.10)$ [electronic supplementary material C]. Interaction effects between health and income dummy variables were not significant for any of the policies (results not shown), thus the final models included only the main effects of health and income. When we investigated the likelihood of support for population subgroups, we found that the average predicted probabilities of policy support were higher (as expected) for less-healthy individuals compared with healthy individuals, in each income group, and the differences were statistically significant for all border control policies $(p<0.10)$. We then investigated the income effect for less-healthy and 


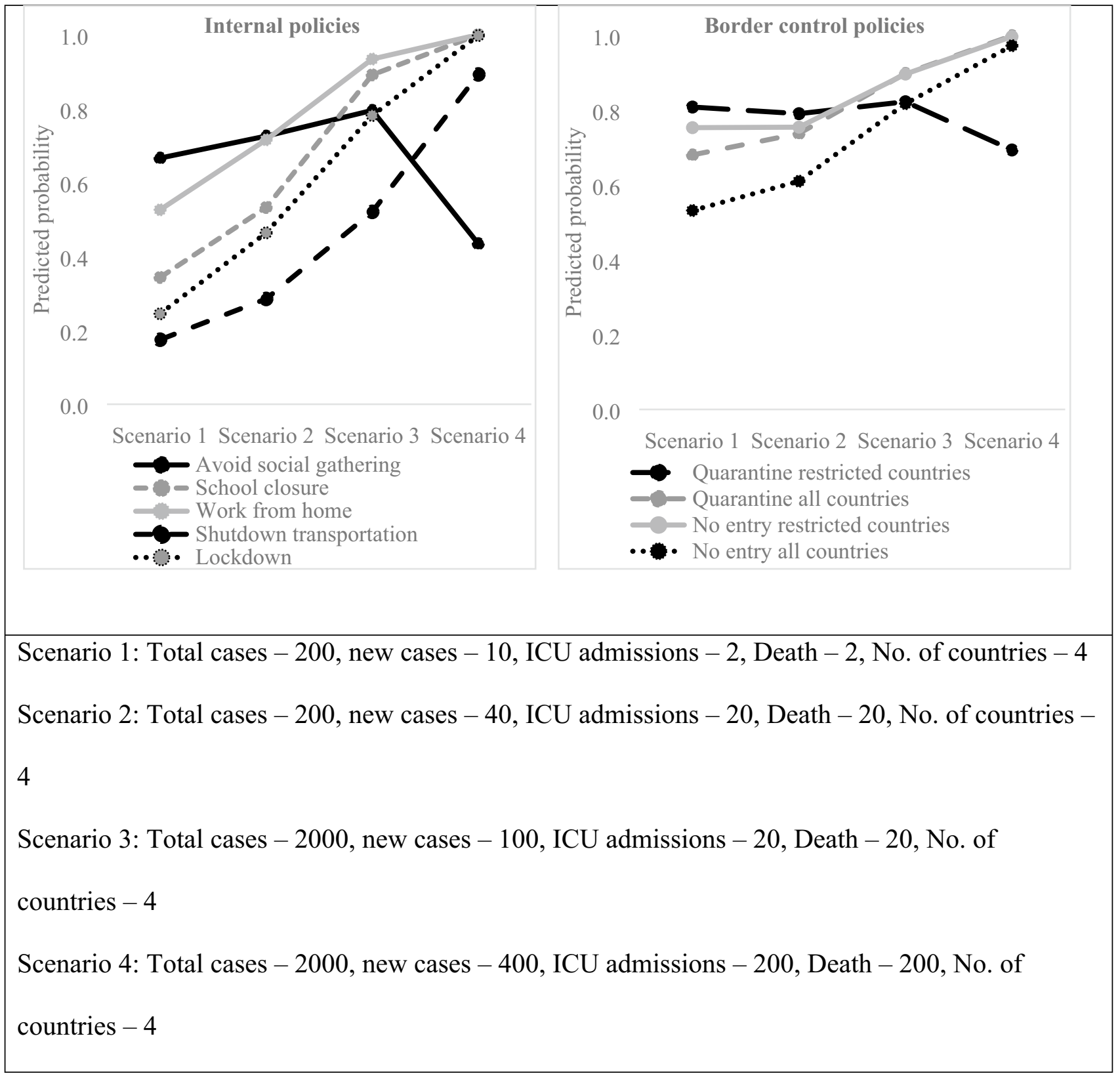

Fig. 2 Average predicted probability of support for a policy for varying levels of outbreak severity

healthy individuals by comparing lower- and middle-income groups with the higher-income group. We found that the average predicted probabilities were lower (as expected) for the lower-income group compared with the higher-income group, and the differences were significant for both lesshealthy and healthy individuals for only two border control policies $(p<0.05)$. The average predicted probabilities were not significantly different between the middle-income group and the higher-income group (for both less-healthy and healthy individuals) for any policy $(p>0.10)$ [see Table 4 for differences in the average predicted probabilities, and electronic supplementary material $\mathrm{E}$ for the full list].

Our findings show that older (vs. younger) patients were more likely to support banning large gatherings, working from home, and all border control policies, while they were less likely to support shutting down public transportation ( $p<0.10$ for all). The average marginal effects of age were largest for banning visitors from selected countries $(0.0031$, $p<0.01)$ and banning large gatherings $(0.0029, p<0.01)$ [electronic supplementary material F]. 


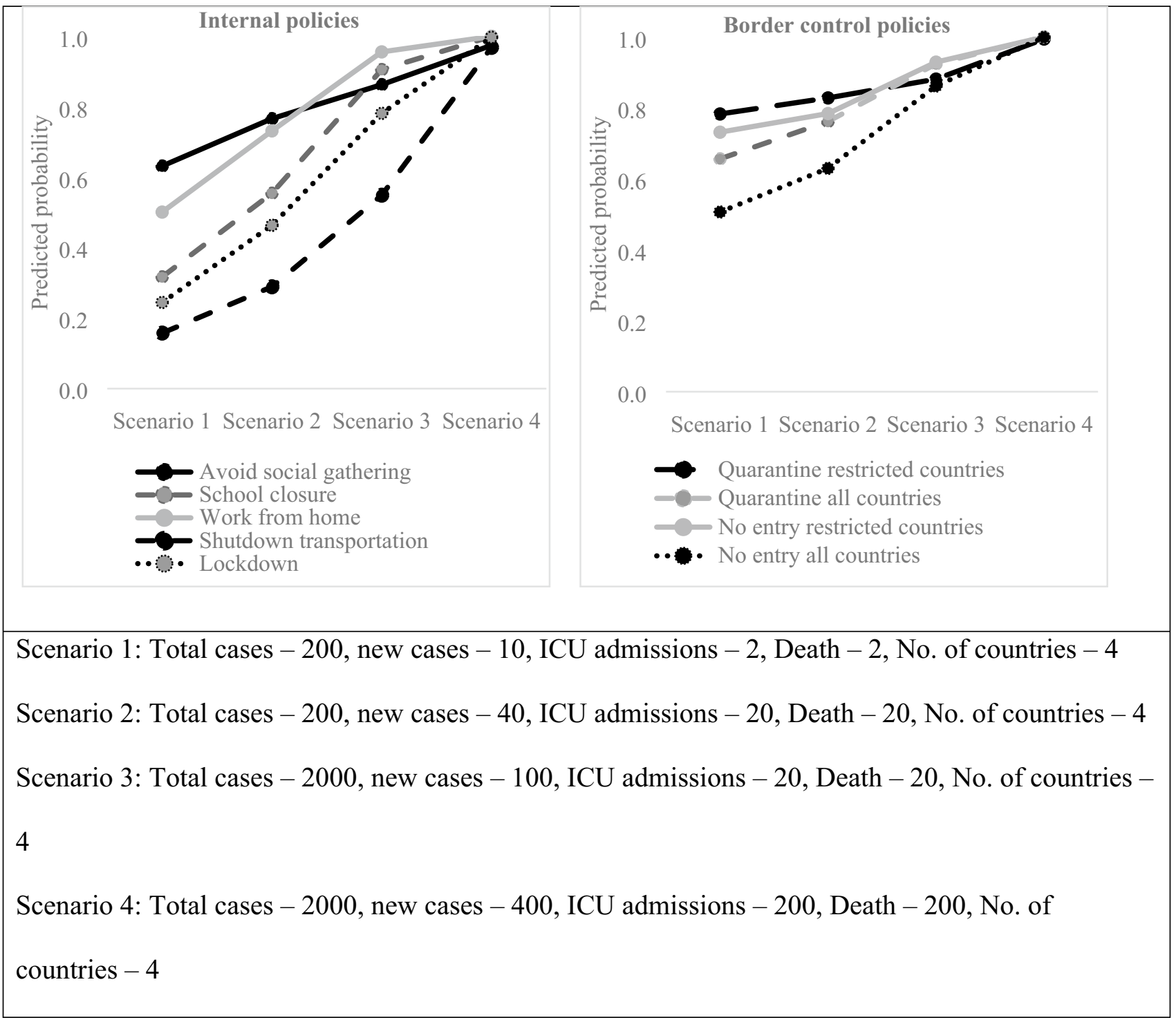

Fig. 3 Sensitivity analysis: average predicted probability of support for a policy for varying levels of outbreak severity after excluding responses that failed the validity test

The probabilities of support were significantly higher for all policies for individuals who perceived the policy to be 'very effective' compared with those who did not $(p<0.01)$. The largest average marginal effects were for banning all visitors $(0.2510, p<0.01)$ and for shutting down public transportation $(0.2296, p<0.01)$. The smallest average marginal effect was for banning large gatherings $(0.0847$, $p<0.01$ ) [electronic supplementary material F].

Respondents living with young children (vs. those not living with young children) were more likely to support national lockdown $(p<0.05)$ but not school closure $(p>0.10)$. Those who completed the survey during the partial lockdown were less likely to support working from home $(p<0.05)$.

\section{Discussion}

We investigated the extent to which the likelihood of support for government outbreak response policies varies with outbreak severity using hypothetical vignettes. We also investigated how the likelihood of support varies by health, income, age, living with young children and perceived effectiveness of a policy. One of the main findings in this study was that the probability of support for any particular policy was primarily driven by an individual's perception of a policy's effectiveness as an outbreak control strategy as well as outbreak characteristics. This is an important finding as (with the exception of Cook et al. [8]) previous studies [6, 7, 9] did not incorporate outbreak severity when investigating 
Table 4 Differences in average predicted probabilities for subgroups, based on health and income $[N=1017]$

\begin{tabular}{|c|c|c|c|c|c|c|c|}
\hline & \multirow{2}{*}{\multicolumn{3}{|c|}{ Health effect ${ }^{a}$}} & \multicolumn{4}{|c|}{ Income effect $^{\mathrm{b}}$} \\
\hline & & & & \multicolumn{2}{|c|}{$\begin{array}{l}\text { Middle- vs. higher- } \\
\text { income }\end{array}$} & \multicolumn{2}{|c|}{$\begin{array}{l}\text { Lower- vs. higher- } \\
\text { income }\end{array}$} \\
\hline & $\begin{array}{l}\text { Higher- } \\
\text { income }\end{array}$ & $\begin{array}{l}\text { Middle- } \\
\text { income }\end{array}$ & Lower-income & Healthy & Less healthy & Healthy & Less healthy \\
\hline \multicolumn{8}{|c|}{ No gatherings of more than 50 people } \\
\hline D-APP & 0.02 & 0.02 & 0.02 & -0.01 & -0.01 & 0.00 & 0.00 \\
\hline$p$ value & 0.56 & 0.56 & 0.56 & 0.77 & 0.77 & 0.91 & 0.91 \\
\hline \multicolumn{8}{|c|}{ School closure } \\
\hline D-APP & 0.03 & 0.03 & 0.03 & 0.01 & 0.01 & 0.03 & 0.03 \\
\hline$p$ value & 0.35 & 0.35 & 0.35 & 0.69 & 0.71 & 0.37 & 0.37 \\
\hline \multicolumn{8}{|c|}{ Work from home orders } \\
\hline D-APP & 0.02 & 0.02 & 0.02 & 0.02 & 0.02 & 0.00 & 0.00 \\
\hline$p$ value & 0.34 & 0.34 & 0.34 & 0.51 & 0.51 & 0.98 & 0.98 \\
\hline \multicolumn{8}{|c|}{ Shut down public transportation } \\
\hline D-APP & 0.02 & 0.02 & 0.02 & 0.01 & 0.01 & 0.01 & 0.01 \\
\hline$p$ value & 0.46 & 0.46 & 0.46 & 0.71 & 0.71 & 0.68 & 0.68 \\
\hline \multicolumn{8}{|c|}{ Lockdown } \\
\hline D-APP & 0.05 & 0.05 & 0.05 & -0.01 & -0.01 & 0.02 & 0.02 \\
\hline$p$ value & 0.14 & 0.14 & 0.14 & 0.75 & 0.75 & 0.53 & 0.53 \\
\hline \multicolumn{8}{|c|}{ Quarantining residents returning from selected countries } \\
\hline D-APP & 0.05 & 0.06 & 0.07 & -0.03 & -0.02 & -0.06 & -0.05 \\
\hline$p$ value & 0.01 & 0.01 & 0.01 & 0.19 & 0.18 & 0.05 & 0.04 \\
\hline \multicolumn{8}{|c|}{ Quarantining residents returning from any country } \\
\hline D-APP & 0.04 & 0.05 & 0.05 & -0.01 & -0.01 & -0.03 & -0.03 \\
\hline$p$ value & 0.07 & 0.08 & 0.08 & 0.67 & 0.67 & 0.31 & 0.31 \\
\hline \multicolumn{8}{|c|}{ No entry of visitors from selected countries } \\
\hline D-APP & 0.06 & 0.06 & 0.07 & 0.00 & 0.00 & -0.07 & -0.06 \\
\hline$p$ value & 0.00 & 0.00 & 0.00 & 0.93 & 0.93 & 0.03 & 0.03 \\
\hline \multicolumn{8}{|c|}{ No entry of visitors from any country } \\
\hline D-APP & 0.08 & 0.08 & 0.08 & 0.01 & 0.00 & -0.03 & \\
\hline$p$ value & 0.00 & 0.00 & 0.00 & 0.84 & 0.84 & 0.34 & 0.34 \\
\hline
\end{tabular}

$D-A P P$ differences in average predicted probabilities

${ }^{a}$ Health effects test as to whether the average predicted probabilities were different between less-healthy and healthier individuals in each income group

${ }^{b}$ Income effects test as to whether the average predicted probabilities were different between the (1) lowand high-income groups, and (2) middle- and high-income groups, for both less-healthy and healthier individuals

public support for government response measures. We also found that the probabilities of support for all policies were greater for scenarios where the outbreak was more severe. These findings suggest that governments should be mindful that the public's support for policies may change as an outbreak evolves.

Consistent with our hypotheses, fatality rate was the most influential factor among outbreak attributes for most internal policies, while global disease spread was the most influential factor for border control policies, on average (based on the attribute levels used in this study). These findings suggest that individuals are less worried about the spread of the infection as long as the disease is not fatal. However, findings might have been different if we chose a much larger spread of the infection. In addition, unsurprisingly, the situation across the world became more important when it came to controlling the borders against visitors or residents coming back from other countries.

In less severe outbreak scenarios, the lowest support was for shutting down public transport (30.4\%). This could be explained by the low car ownership rate of approximately 10\% (as of 2018) in Singapore (compared with approximately $80 \%$ in the US and just slightly below $50 \%$ in Europe [27]). This finding would be relevant to other 
large cities where public transport is the main mode of travel, such as Seoul [28] or New York City [29].

Unsurprisingly, a lockdown of all citizens received the second lowest level of support (45.1\%) due to the disruption it would cause to everyone's daily life. In the case of a lockdown, those with jobs that do not allow the possibility of working from home may face a loss of income. None of the other aforementioned studies [6, 7,9] explored support for a policy on the lockdown of all residents.

Restricting social gatherings received the highest support among internal policies (74.3\%), likely because it was the least restrictive internal policy presented in our study. Overall, the lower levels of support for restrictive internal policies suggest that governments have to invest effort in designing targeted public health messages explaining to the public why these measures are necessary and how they can help with outbreak response efforts.

Border control policies received greater support than policies for internal restrictions for any given outbreak scenario. There might be several reasons for this. First, border control affects daily life less than internal control policies for most individuals. Second, individuals could be lacking understanding on the effectiveness of different policies. Disallowing social gatherings was perceived to be very effective by only $39 \%$ of our sample, compared with the $67-76 \%$ who found border control policies to be very effective. However, previous literature has suggested that social distancing is considerably more effective at transmission control than restricting borders [30-32]. Lastly, the occurrence of a disease outbreak is often associated with higher levels of ethnocentrism and xenophobia [33, 34].

We found that 'number of countries with rapidly increasing cases' was one of the main determinants of the likelihood of support for restricting the entry of visitors or quarantine of residents returning from any country. This is understandable because more countries reporting rapidly increasing numbers indicates higher rates of transmission across the world. This finding is also consistent with the response adopted by governments around the world during COVID19. As COVID-19 cases were detected in more countries, governments implemented stricter border control measures.

We also found that the individual's perception of a policy's effectiveness as an outbreak control strategy was the most consistent predictor of support for all policies in our study. This is a noteworthy finding with important policy implications for governments. Our findings suggest that governments can focus on perceptions about the effectiveness of a policy to gain support from the public. Future studies can investigate how public perceptions are influenced to increase public compliance to and support for a policy.

Among personal characteristics, less-healthy individuals (vs. healthier individuals) were more likely to support all four border control policies, while individuals with lowerincome (vs. higher-income) were less likely to support two border control policies. We observed a health effect where less-healthy individuals had greater support for policies compared with healthier individuals in each income group, although the differences were significant only for the border control policies. This may be because less-healthy individuals perceive themselves to be at higher risk of infection [35], and hence support border control policies, which still have smaller effects on income and daily lives compared with internal policies (such as national lockdown). On the other hand, we observed an income effect among both less-healthy and healthier individuals for the lower-income group only (in comparison with the higher-income group) for the two border control policies. These findings suggest that, for our sample, health concerns seem to outweigh income concerns during an outbreak. However, results may also be driven by a lack of power, and future research should test whether these findings hold in other countries.

Age was found to be a significant predictor of the likelihood of support for most policies. Older individuals (vs. younger individuals) were more likely to support most policies compared with those who were younger, with the exception of shutting down public transportation, which older individuals were less likely to support. The finding on shutting down transportation is not unexpected as 50.4\% of car owners in Singapore are aged 30-39 years, which is higher than most age groups [36]. Overall, since older individuals were, in general, more likely to support response policies, public health messages should be tailored to appeal to younger ages.

We also found that living with young children was a significant predictor of the likelihood of support for national lockdown, but not for school closure. It is possible that some individuals with young children might prefer their children to continue going to the school in order not to interrupt their education and/or ability to earn income, or not to have to pay for childcare [37]. Those who completed the survey during the partial lockdown were less likely to support working from home. This may be due to the negative effects of real-time working-from-home experience during the partial lockdown.

The main limitation of our study is that some of our findings may not be generalizable beyond Singapore, especially not to more individualistic societies. In Singapore, trust in the government and compliance with government policies is high in general. This is also likely in other developed Asian countries such as China and Japan. Thus, Singaporeans and citizens of similar nations are more likely to support and comply with these policies compared with some Western nations. Additionally, our study sample overrepresents those with university or higher education, and who are tech savvy. However, conducting a web survey enabled 
us to collect time-sensitive information quicker than other methods of data collection. Our study findings are also based on hypothetical vignettes, and individuals' preferences may be different during real outbreak situations; however, we minimized the effects of this limitation by implementing the study during the COVID-19 pandemic. Lastly, the list of outbreak control policies shown in the vignette scenarios were always presented in the same order to reduce the cognitive burden on respondents, which could have caused a possible ordering bias in favor of the policies shown earlier in the order.

\section{Conclusion}

Our study is one of the first to investigate the likelihood of support for government policies in response to varying infectious disease outbreaks, and is the first study to investigate public support for very restrictive policies such as lockdown. Our findings showed that the likelihood of support varied across government response policies, but was generally higher for border control policies compared with internal policies. Individuals were willing to support even the most restrictive policies when the outbreak was severe. The fatality rate was the most important factor for internal policies, while the degree of global spread was the most important for border control policies. Our findings suggest that campaigns to promote public support and compliance should be designed specifically to each policy, and tailored to different segments of the population. They should also be adapted based on the evolving conditions in order to receive continued public support.

Supplementary Information The online version of this article (https:// doi.org/10.1007/s40271-020-00494-9) contains supplementary material, which is available to authorized users.

Acknowledgements The authors would like to thank Dr. Irene Teo for her feedback on the questionnaire.

\section{Declarations}

Conflict of interest Semra Ozdemir, Si Ning Germaine Tan, Isha Chaudhry, Chetna Maholtra, and Eric Andrew Finkelstein have no conflicts of interests to declare.

Funding This study was funded by the Lien Centre for Palliative Care (N-911-000-030-091).

Ethics approval The study was exempted from ethics review by the Institutional Review Board of National University of Singapore (Application Reference Number: S-20-085).
Consent to participate All participants consented to participate in this study.

Consent for publication All authors consent to the publication of this study.

Data availability Data used in this study are available from the corresponding author upon reasonable request.

Code availability Codes used in this study are available from the corresponding author upon reasonable request.

Author contributions All authors contributed to the writing and/or critical review of this manuscript.

\section{References}

1. Gostin LO, Bayer R, Fairchild AL. Ethical and legal challenges posed by severe acute respiratory syndrome: implications for the control of severe infectious disease threats. JAMA. 2003;290(24):3229-37.

2. Wynia MK. Ethics and public health emergencies: restrictions on liberty. Am J Bioethics. 2007;7(2):1-5.

3. Smith RD. Responding to global infectious disease outbreaks: lessons from SARS on the role of risk perception, communication and management. Soc Sci Med. 2006;63(12):3113-23.

4. Der Heide EA, Irwin RL. Disaster response: principles of preparation and coordination. St Louis: Mosby; 1989.

5. McEntire DA, Myers A. Preparing communities for disasters: issues and processes for government readiness. Disast Prev Manag. 2004;13(2):140-52.

6. Paek HJ, et al. Public support for government actions during a flu pandemic: lessons learned from a statewide survey. Health Promot Pract. 2008;9(4 Suppl):60S-72S.

7. Blendon RJ, et al. Attitudes toward the use of quarantine in a public health emergency in four countries: the experiences of Hong Kong, Singapore, Taiwan, and the United States are instructive in assessing national responses to disease threats. Health Aff. 2006;25(Suppl 1):W15-25.

8. Cook AR, et al. Public preferences for interventions to prevent emerging infectious disease threats: a discrete choice experiment. BMJ Open. 2018;8(2):e017355.

9. Hilyard KM, et al. The vagaries of public support for government actions in case of a pandemic. Health Aff. 2010;29(12):2294-301.

10. Zhang D, Hu M, Ji Q. Financial markets under the global pandemic of COVID-19. Finance Res Lett. 2020;36:101528.

11. Chew NW, et al. A multinational, multicentre study on the psychological outcomes and associated physical symptoms amongst healthcare workers during COVID-19 outbreak. Brain Behav Immun. 2020;88:559-65.

12. Dubey S, et al. Psychosocial impact of COVID-19. Diabetes Metab Syndrome. 2020;14(5):779-88.

13. Rasappan K, et al. A surgeon's role in fighting a medical pandemic: experiences from the unit at the epicentre of COVID-19 in Singapore-a cohort perspective. Int J Surg. 2020;79:31-5.

14. Funk CL. The dual influence of self-interest and societal interest in public opinion. Polit Res Q. 2000;53(1):37-62.

15. DiGiovanni $\mathrm{C}$, et al. Factors influencing compliance with quarantine in Toronto during the 2003 SARS outbreak. Biosecur Bioterror. 2004;2(4):265-72.

16. Barker WH, Borisute H, Cox C. A study of the impact of influenza on the functional status of frail older people. Arch Intern Med. 1998;158(6):645-50. 
17. Nicholson KG, Wood JM, Zambon M. Influenza. Lancet. 2003;362(9397):1733-45.

18. Faust SN, Munro AP. It's time to put children and young people first during the global COVID-19 pandemic. JAMA Pediatr. 2021. https://doi.org/10.1001/jamapediatrics.2020.4582 (Epub 25 Sep 2020).

19. Brom C, et al. Mandatory home education during the COVID19 lockdown in the Czech Republic: a rapid survey of 1st-9th graders' parents. Front Educ. 2020. https://doi.org/10.3389/feduc. 2020.00103 (Epub 9 Jul 2020).

20. Lau J, et al. Monitoring community responses to the SARS epidemic in Hong Kong: from day 10 to day 62. J Epidemiol Commun Health. 2003;57(11):864-70.

21. Lau JT, et al. SARS preventive and risk behaviours of Hong Kong air travellers. Epidemiol Infect. 2004;132(4):727-36.

22. CAN. 47 new COVID-19 cases in Singapore, new cluster identified at dormitory in Toh Guan. CAN; 2020.

23. StataCorp LLC. Stata base reference manual. College Station: StataCorp LLC.; 2005.

24. Jann B. Predictive margins and marginal effects in Stata. IDEAS; 2013.

25. Department of Statistics, Singapore. Population Trends. 2019. http://www.singstat.gov.sg. Accessed 18 Dec 2020.

26. Department of Statistics, Singapore. Households. 2020. http:// Singstat.gov.sg. Accessed 18 Dec 2020.

27. Budget Direct Insurance. Car Ownership in Singapore. 2019. https://www.budgetdirect.com.sg/car-insurance/research/carownership-singapore-2019.
28. Seoul Metropolitan Government. Seoul Public Transportation. Seoul. Seoul Metropolitan Government; 2012.

29. CNN Editorial Research. Metropolitan transportation authority fast facts. CNN Editorial Research; 2020.

30. Collignon PJ, Carnie JA. Infection control and pandemic influenza. Med J Aust. 2006;185(10):S54.

31. Ferguson NM, et al. Strategies for mitigating an influenza pandemic. Nature. 2006;442(7101):448-52.

32. Glass RJ, et al. Targeted social distancing designs for pandemic influenza. Emerg Infect Dis. 2006;12(11):1671.

33. Schaller M, Neuberg SL. Danger, disease, and the nature of prejudice(s). In: Advances in experimental social psychology, vol. 46. Academic Press; 2012. pp. 1-54.

34. Van Bavel JJ, et al. Using social and behavioural science to support COVID-19 pandemic response. Nat Hum Behav. 2020;4:460-71.

35. Wolf MS, et al. Awareness, attitudes, and actions related to COVID-19 among adults with chronic conditions at the onset of the US outbreak: a cross-sectional survey. Ann Intern Med. 2020;173(2):100-9.

36. Ting FW, Renting H. Households' spending by age group. Singapore Department of Statistics, Income Expensiture Division; 2016.

37. Dong C, Cao S, Li H. Young children's online learning during COVID-19 pandemic: Chinese parents' beliefs and attitudes. Child Youth Serv Rev. 2020;118:105440. 